\title{
NOTA TÉCNICA \\ INFLUENCIA DE CUATRO DIETAS INERTES EN EL CRECIMIENTO DEL CÍCLIDO ENANO Apistogramma eunotus (PERCIFORMES, CICHLIDAE)
}

\author{
Leticia GONZÁLES DEL ÁGUILA ${ }^{1,2}$, Luis MORI-PINEDO ${ }^{1}$, Enrique RÍOS ISERN ${ }^{1}$, Rosa ISMIÑO ORBE ${ }^{2}$, Fred \\ CHU-KOO ${ }^{2}$ \\ 1 Universidad Nacional de la Amazonía Peruana - UNAP. Facultad de Ciencias Biológicas. Calle Pevas s/n. Iquitos, Loreto, Perú. \\ 2 Instituto de Investigaciones de la Amazonía Peruana - IIAP. Programa para el Uso y Conservación del Agua y sus Recursos - \\ AQUAREC. Carretera lquitos - Nauta Km 4.5. San Juan Bautista, Loreto, Perú. E-mail: fchuk20@gmail.com.
}

\section{RESUMEN}

El estudio tuvo como objetivo evaluar el crecimiento de juveniles de Apistogramma eunotus, alimentados con cuatro dietas inertes $(\mathrm{T} 1=$ IIAP Pellet, $\mathrm{T} 2=$ Pellet NutraFin, $\mathrm{T} 3=$ Hojuela NutraFin y T4 $=$ Hojuela Sera $)$. Un total de 120 ejemplares de $A$. eunotus fueron distribuidos en grupos de 10 individuos, colocados dentro de 12 acuarios y alimentados con una tasa de alimentación equivalente al $6 \%$ de la biomasa presente en cada acuario diariamente, durante 77 días. El crecimiento de A. eunotus en términos de peso final, TCR y TCE, fue influenciado significativamente $(\mathrm{P}<0.05)$ por la dieta Hojuela NutraFin. En términos de conversión alimenticia, los peces no fueron eficientes asimilando las dietas que les fueron ofertadas. El desempeño productivo de los peces alimentados con la dieta Pellet IIAP fue similar $(\mathrm{P}>0.05)$ a la de los peces nutridos con la dieta Hojuela Sera, un descubrimiento que puede ayudar a reducir los costos de alimentación en los acuarios de la ciudad de Iquitos.

PALABRAS CLAVE: Apistogramma eunotus, dietas, alimentación, crecimiento, sobrevivencia.

\section{INFLUENCE OF FOUR INERT DIETS ON GROWTH OF THE DWARF CICHLID Apistogramma eunotus (PERCIFORMES, CICHLIDAE)}

\begin{abstract}
The study aimed to evaluate the growth of juvenile Apistogramma eunotus, fed with four inert diets during 77 days. A total of 120 fish were distributed in groups of 10 individuals into 12 aquaria and fed daily applying a feeding rate equivalent to $6 \%$ of the fish biomass presented in each aquarium, during 77 days. Growth of A. eunotus expressed in terms of final weight, relative growth rate and specific growth rate, was significantly influenced $(\mathrm{P}<0.05)$ by the Flake NutraFin diet. In terms of feed conversion, the fishes were not efficient assimilating the experimental diets. Yield performance recorded in fish fed the Pellet IIAP diet was similar $(\mathrm{P}>0.05)$ to those registered for fishes fed with Flake Sera diet, a discovery that may help to reduce the feeding costs in most ornamental processing factories located in Iquitos City.
\end{abstract}

KEYWORDS: Apistogramma eunotus, diets, feeding, growth, survival. 
Los peces ornamentales constituyen recursos naturales cuya comercialización provee de empleo formal e informal a cerca de 20,000 personas y genera rentas hasta por cinco millones de dólares/año en la región Loreto (Ruiz et al., 2003; BCRP, 2010). La captura anual de peces ornamentales en la región Loreto, fluctuó entre los 5'817,006 a 11'461,922 unidades extraídas entre los años 2000 a 2010, los mismos que fueron exportados a Estados Unidos, Europa y varios destinos asiáticos (García et al., 2011). Considerando que la mayoría de los peces ornamentales permanecen entre 7 a 60 días en las casas acuaristas de Iquitos, se estima que localmente existe una buena demanda por alimentos vivos e inertes para la manutención de dichos animales.

Como en toda actividad que involucre la crianza de animales, la alimentación es un factor crítico en la acuariofilia. Moreau \& Coomes (2007), reportan que la alta mortandad observada en las casas acuaristas (conjunto de acopiadores y exportadores de peces ornamentales) en la Amazonía peruana, se debieron a tres factores fundamentales: i) las rudimentarias formas de transporte, ii) pésimas instalaciones de manejo, y la iii) inadecuada alimentación de los peces, traídos en su totalidad del medio natural. A pesar del tiempo transcurrido, éste dramático panorama se mantiene hasta la fecha, con algunas honrosas excepciones.

En la actualidad, una alta variedad de alimentos inertes como yema de huevo en suspensión, leche y raciones en polvo, y vivos, como el plancton natural, micro crustáceos, larvas de zancudo, Moina y Tubifex, son empleados para garantizar una buena manutención de peces ornamentales (Lim et al., 2003; Alcántara et al., 2009). Sin embargo, el uso de alimentos balanceados posibilitan reducir la costosa dependencia de los quistes y náuplios de Artemia (Wousters et al., 2004).

Moreau \& Coomes (2007) reportan que del Perú se comercializan 704 variedades de peces, de 139 géneros y 36 familias, encontrándose entre ellos a los cíclidos del género Apistogramma (Gerstner et al., 2006), conocidos como cíclidos enanos.

Evidencias recientes indican que este grupo de cíclidos es más diverso de lo que se conoce en la actualidad. Recientemente, la riqueza específica ha ido en aumento con el descubrimiento de cuatro nuevas especies en la Amazonía peruana: A. barlowi, A. cinilabra, A. eremnopyge y A. playayacu (Romer \& Hahn, 2008; Ready \& Kullander, 2004; Romer et al., 2011). Colectas recientes realizadas por especialistas del Laboratorio Mixto Internacional EDIA (IRD -IIAP), en cuerpos de agua de Loreto, han reportado varios especímenes Apistogramma con características fenotípicas aún no conocidas, que seguramente derivarán en la descripción de nuevas especies.
En la presente investigación se evaluó el crecimiento del cíclido Apistogramma eunotus, alimentado con cuatro dietas balanceadas, tres de ellas disponibles en el mercado internacional y una formulada en el IIAP utilizando insumos tradicionales más la adición de la microalga Spirulina platensis, con la pretensión futura de producir y ofertar un alimento competente en calidad y precio para el mercado local de peces ornamentales.

El trabajo fue realizado en el Centro de Investigaciones Quistococha del Instituto de Investigaciones de la Amazonía Peruana - IIAP, localizado en el Km. 4.5 de la Carretera Iquitos Nauta (Provincia de Maynas, departamento de Loreto). Se utilizó un total de 120 juveniles de Apistogramma eunotus, de $0.48 \mathrm{~g}$ de peso y $15 \mathrm{~mm}$ de longitud inicial, respectivamente, provenientes de la cuenca del río Nanay.

Las cuatro dietas empleadas como tratamientos fueron: $\mathrm{T} 1=$ Pellet IIAP, $\mathrm{T} 2=$ Pellet NutraFin, $\mathrm{T} 3=$ Hojuela NutraFin y T4 = Hojuela Sera. De las cuatro dietas seleccionadas, las tres últimas pertenecen a marcas extranjeras disponibles en el mercado nacional, mientras que la primera, es una ración formulada en el IIAP. La composición nutricional de las cuatro dietas utilizadas en el experimento se muestra en la Tabla 1.

Se emplearon 12 acuarios de vidrio de 100 litros. Se sembraron 10 peces por cada acuario, los mismos que permanecieron por dos semanas en etapa de aclimatación. Los tratamientos dietarios fueron aleatoriamente asignados entre los 12 acuarios por triplicado. Los peces fueron alimentados dos veces al día $(8.30$ y $14.30 \mathrm{~h})$, aplicándose una tasa de alimentación diaria equivalente al $6 \%$ de la biomasa existente en cada acuario, los 7 días de la semana. La fase experimental tuvo una duración total de 77 días (11 semanas).

Diariamente se realizó la limpieza de los acuarios una hora post-alimentación a través del método del sifoneo del fondo, colectando los restos de alimento y heces que se acumulaban en el fondo de los acuarios. Finalizada la limpieza, se reponía el agua hasta los niveles normales (aproximadamente unos 70 litros). Dos veces por día ( $8: 00$ y $14.00 \mathrm{~h}$ ) se tomaron medidas de la temperatura del agua, $\mathrm{pH}$ y oxígeno disuelto con la ayuda de un oxímetro YSI MPS 556. Quincenalmente se evaluaron los niveles de amonio, nitrito y dureza total del agua de los acuarios con la ayuda de un Kit LaMotte AQ-2 para análisis de aguas dulces. Semanalmente se realizaron muestreos biométricos del $100 \%$ de la población presente en cada acuario con la ayuda de una balanza digital marca OHAUS ${ }^{\circledR}$ y un ictiómetro graduado en milímetros. 
Se calcularon los siguientes índices zootécnicos: Peso final (PF), Longitud final (LF), Tasa de Crecimiento Relativo (\% TCR), Tasa de Crecimiento Específico (\%TCE), Factor de Condición (K), Tasa de Sobrevivencia, y el Índice de Conversión Alimenticia Aparente (ICAA). Para el cálculo de los ICAA, se consideró un reajuste a la cantidad total de alimento consumido por los peces de cada unidad experimental, a raíz del significativo porcentaje de alimento que no era consumido por los peces de algunas réplicas. Los datos fueron procesados en hojas de Excel y los resultados analizados a través de ANOVA simple. Cuando el ANOVA detectó diferencias significativas, se aplicó la prueba de comparación múltiple de promedios de Tukey $($ alpha $=0.05)$ con la ayuda del programa estadístico JMP IN versión 4.0.4. Los resultados son mostrados como el promedio \pm la desviación estándar de la media.

Los registros semanales de oxígeno disuelto en los acuarios varió entre 6.21 y $6.9 \mathrm{mg} / \mathrm{l}$ (promedio $=6.54$ $\mathrm{mg} / \mathrm{l})$, la temperatura entre 25.8 y $27.3 \mathrm{C}^{\mathrm{o}}$ (promedio $=$ $26.65^{\circ} \mathrm{C}$ ) y los niveles de $\mathrm{pH}$ entre 7.3 y 7.6 (promedio $=7.49$ ). Las mediciones quincenales de amonio, mostraron niveles entre 0.2 y $0.6 \mathrm{ppm}$ (promedio $=$ $0.26 \mathrm{ppm}$ ), mientras que los nitritos variaron entre 0.05 y $0.6 \mathrm{ppm}$ (promedio $=0.09 \mathrm{ppm}$ ). Finalmente, las concentraciones de dureza total oscilaron entre $9 \mathrm{y}$ $10.4 \mathrm{ppm}$ (promedio $=9.26 \mathrm{ppm}$ ). Al comparar nuestros reportes de calidad de agua con otros estudios de ecología y acuicultura realizados en esta especie (Soriano \& Hernández, 2002; Cachay et al., 2006; Rodrigues \& Fernandes, 2006), podemos inferir que estos parámetros no se constituyeron en factores limitantes que hayan repercutido negativamente en el crecimiento de los peces.

Los peces alimentados con la dieta T3 (Hojuela NutraFin), tuvieron un crecimiento superior (Tabla 2) a los individuos de los tratamientos restantes. Diferencias estadísticas significativas $(\mathrm{P}<0.05)$ fueron encontradas en las siguientes variables: peso final $(\mathrm{P}<0.001)$, longitud final $(\mathrm{P}=0.0017)$, tasa de crecimiento relativo $(\mathrm{P}<0.001)$, tasa de crecimiento específico $(\mathrm{P}=0.001)$, índice de conversión alimenticia aparente $(\mathrm{P}<0.001)$, eficiencia alimenticia $(\mathrm{P}=0.002)$, y factor de condición ( $\mathrm{P}=0.020)$. El único índice zootécnico que se mantuvo homogéneo hasta finalizar el estudio, fue la tasa de sobrevivencia $(\mathrm{P}=0.925)$.

Los resultados del presente trabajo demuestran que los peces alimentados con Hojuela NutraFin, tuvieron el mejor desempeño zootécnico, siguiendo en orden de importancia, las dietas Hojuela Sera y Pellet IIAP. En contraste, la dieta Pellet NutraFin produjo los peores resultados en términos de crecimiento y utilización del alimento.
Aunque tuvo un tenor proteico de solo $42.5 \%$, la dieta Pellet IIAP produjo niveles de crecimiento y conversión alimenticia similares a la Hojuela Sera, la misma que posee mayor concentración proteica $(46.2 \%)$. En acuicultura es generalmente aceptado que una mayor oferta proteica conlleva casi siempre a un mayor incremento de las tasas de crecimiento de los organismos en cultivo (Morias et al., 2001). Un ejemplo de lo previamente mencionado es el trabajo publicado por Chong et al. (2000), quienes al evaluar cinco niveles de proteína bruta $(35,40,45,50$ y $55 \%)$ en dietas para el pez disco (Symphysodon spp.), verificaron por el método de regresión polinomial que las mejores ganancias de peso se obtuvieron a niveles de $50.1 \%$ de proteína dietaria y las mejores tasas de conversión alimenticia a niveles de $44.9 \%$. Sin embargo, al revisar trabajos que puedan dar soporte a nuestros resultados, encontramos un estudio realizado por Maehana et al. (2004), en el pez disco (Symphysodon sp.), quienes no hallaron diferencias significativas en la ganancia de peso en ejemplares juveniles de este pez alimentados con dietas entre 35\% y $50 \%$ de proteína.

En cuanto a la conversión alimenticia (ICAA), se pudo notar una similitud estadística entre las dietas elaboradas en tipo hojuelas (NutraFin y Sera) y la dieta Pellet IIAP, lo cual es un notable descubrimiento, ya que a pesar de que las dietas en hojuelas pasan por un proceso de cocción similar a la extrusión lo que facilita su flotabilidad y digestibilidad (Booth et al., 2000), su asimilación no fue evidentemente superior al Pellet IIAP, como si lo fue con el Pellet NutraFin. En acuariofilia, las dietas del tipo peletizadas son generalmente empleadas para la alimentación de peces de movimientos rápidos, capaces de perseguir y capturar los pellets en hundimiento. También se usan para la alimentación de peces que se localizan u ocupan los estratos inferiores de los acuarios como por ejemplo los loricáridos. Sin embargo, funcionaron relativamente bien con A. eunotus.

Los ICAA obtenidos en el presente trabajo son altos si consideramos a los organismos evaluados. Los peces son conocidos por ser eficientes en la utilización y asimilación de una amplia variedad de ítems alimenticios tanto en la naturaleza como en condiciones de cautiverio, por lo que los niveles de conversión alimenticia reportados en el estudio, podrían ser considerados inadecuados para fines acuícolas. El constante y difícil manipuleo de los ejemplares, durante los muestreos biométricos, debió haber ocasionado situaciones de estrés fisiológico prolongado, afectando el apetito y la asimilación de los nutrientes en éstos pequeños cíclidos.

Tradicionalmente, los insumos alimentarios más empleados en acuariofilia son alimentos inertes como 
yemas de huevo en suspensión y raciones en polvo, así como el plancton natural y Tubifex (Lim et al., 2003). También es frecuente el empleo de Artemia spp. y varios tipos de alimentos vivos como las larvas de zancudos y peces de pequeño porte (Alcántara et al., 2009). Sin embargo, el presente estudio mostró que el uso de dietas inertes también es una estrategia válida, puesto que el empleo de alimentos inertes optimiza el crecimiento (García-Ulloa \& Gómez-Romero, 2005), impacta menos la calidad del agua (Santos et al., 2008), reduce el riesgo de transmisión de enfermedades (Negrete et al., 2008), y además, posibilita reducir la costosa dependencia de los quistes de Artemia.

En lo que respecta a los niveles de sobrevivencia, debemos mencionar que éstos superaron el $80 \%$ en todas las unidades experimentales, observándose algunas mortalidades posiblemente debido al estrés por el manipuleo en los muestreos biométricos, aspecto que se vio dificultado por el pequeño tamaño de los especímenes. Sin embargo, similares niveles de sobrevivencia fueron reportados también por varios autores que realizaron estudios en otras especies de cíclidos (Soriano \& Hernández, 2002; García-Ulloa \& Gómez-Romero, 2005; Rodrigues \& Fernández, 2006; Luna-Figueroa, 1999; Luna-Figueroa et al., 2000).
El aceptable rendimiento productivo observado en aquellos peces alimentados con la dieta IIAP Pellet, permite visualizar a corto plazo, la aplicación de los resultados de la presente investigación directamente en beneficio de las actividades productivas locales. En Iquitos funcionan 33 empresas dedicadas a la exportación de peces ornamentales, cuyos costos de alimentación de peces son onerosos y que podrían ver incrementadas sus márgenes de ganancias con la utilización de dietas producidas localmente, con precios más competitivos en comparación a las dietas comerciales que son empleadas actualmente. Otro potencial mercado que puede ser proveído con este tipo de dietas lo conforman los miles de aficionados a la crianza de peces ornamentales que existen en Iquitos.

En conclusión, el crecimiento de A. eunotus en términos de peso final, TCR y TCE, fue influenciado significativamente $(\mathrm{P}<0.05)$ por la dieta Hojuela NutraFin. En términos de conversión alimenticia, los peces no fueron eficientes asimilando las dietas que les fueron ofertadas. El desempeño productivo de los peces alimentados con la dieta Pellet IIAP fue similar $(\mathrm{P}>0.05)$ a la de los peces nutridos con la dieta Sera Hojuela, un descubrimiento que puede ayudar a reducir los costos de alimentación en los acuarios de la ciudad de Iquitos.

Tabla 1. Composición nutricional (\%) de cuatro raciones balanceadas utilizados en la alimentación de Apistogramma eunotus (Cichlidae) durante 77 días.

\begin{tabular}{lcccc}
\hline & $\begin{array}{c}\text { T1 - IIAP } \\
\text { (Pellet) }\end{array}$ & $\begin{array}{c}\text { T2 - NUTRAFIN } \\
\text { (Pellet) }\end{array}$ & $\begin{array}{c}\text { T3 - NUTRAFIN } \\
\text { (Hojuela) }\end{array}$ & $\begin{array}{c}\text { T4 - SERA } \\
\text { (Hojuela) }\end{array}$ \\
\hline Proteína (\%) & 42.5 & 45.0 & 45.0 & 46.2 \\
Lípidos (\%) & 6.9 & 3.0 & 3.0 & 8.9 \\
\hline Fibra (\%) & 5.5 & 5.0 & 5.0 & 2.3 \\
Humedad (\%) & 7.3 & 5.0 & 5.0 & 6.7 \\
Ceniza (\%) & 2.23 & 8.03 & 8.0 & 11.9 \\
Carbohidratos (\%) & 5.6 & 4.0 & 34.0 & 23.7 \\
Energía Bruta (Kcal/Kg) & 3740 & 3430 & 3430 & 3590 \\
\hline
\end{tabular}




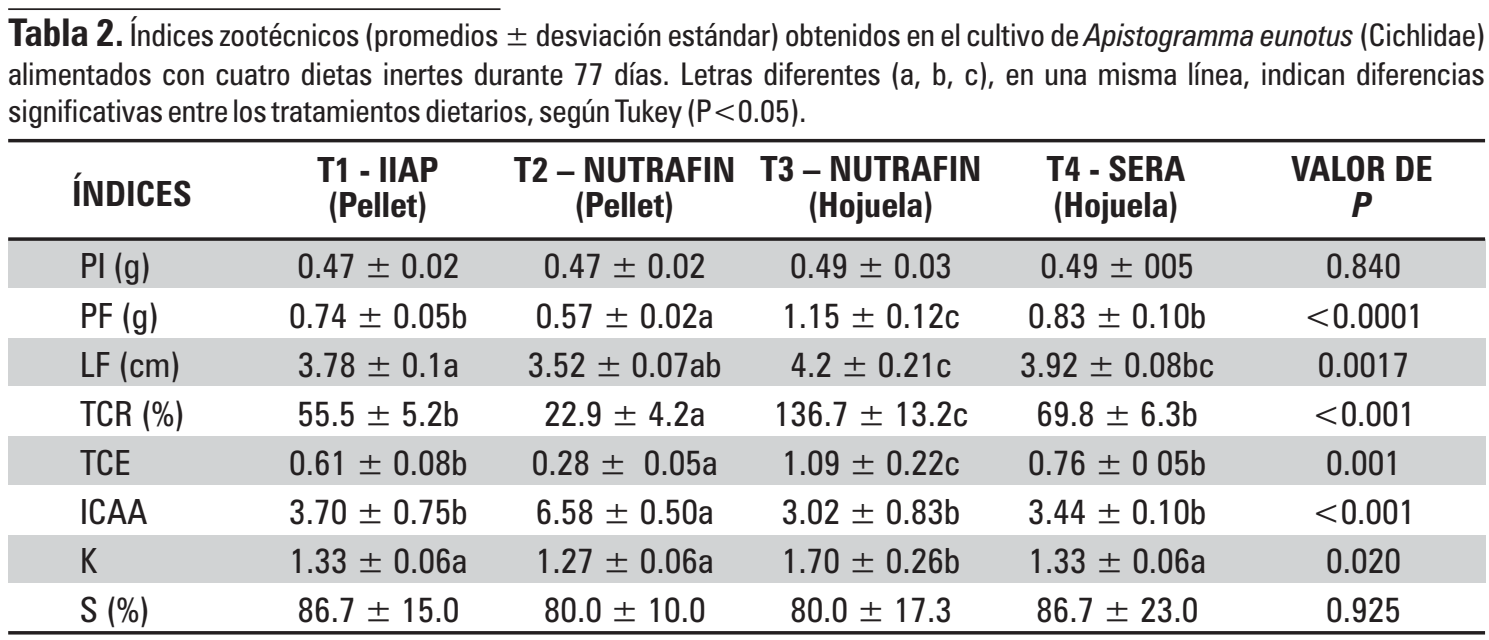

\section{BIBLIOGRAFÍA CITADA}

Alcántara, B.F.; Chu-Koo, F.W. ; Chávez, V.C.A.; Rodríguez, C.L.; Tello, M.S. 2009. Manual de captura y pos captura de peces ornamentales. IIAPCENDIPP. Lima-Perú. 43p.

BCRP (Banco Central de Reserva del Perú). 2010. Síntesis económica de la región Loreto. Banco Central de Reserva del Perú, sede Iquitos. Iquitos Perú. 52p.

Booth, M.A.; Geoff L.A.; Warmer-Smith. 2000. Effects of griding, steam conditioning and extrusion of a practical diet on digestibility and weight gain of silver perch, Bidyanus bidyanus. Aquaculture, 182: 287-299.

Cachay, D.C.; Llontop, V.C.; Sanguinetti, L.C.; Muñoz, L.M.; Melgar del Risco, J. 2006. Captura, adaptación y reproducción de peces ornamentales amazónicos, Apistogramma spp. y Pyrrhulina sp. In: Renno, J-F.; García-Dávila, C.R.; Duponchelle, F.; Núñez, J. (eds.). Biología de las Poblaciones de Peces de la Amazonia y Piscicultura. p.215-221.

Chong, A.S.C.; Hashim, R.; Ali, A.B. 2000. Dietary protein requirements for discus (Symphysodon spp.). Aquaculture Nutrition, 6(4):275-278.

García, V.A. Vargas, G.; Sánchez, H.; Tello, S. 2011. Estado de la pesquería ornamental en la región Loreto entre los años 2000 -2010. In: IIAP (ed.). Memoria Institucional 2011.p. 16.

García-Ulloa, M.; Gómez-Romero, H.J. 2005. Crecimiento de juveniles del pez ángel Pterophyllum scalare (Gunther, 1862) juveniles alimentados con dietas inertes. Avances en Investigación Agropecuaria, 9(3): 49-59.
Gerstner, C. L.; Ortega, H.; Sánchez, H.; Graham, D. L. 2006. Effects of the freshwater aquarium trade on wild fish populations in differentially fished areas of the Peruvian Amazon. Journal of Fish Biology, 68(3): 862-875.

Kullander, S.O. 1981. Description of a new species of Apistogramma (Teleostei: Cichlidae) from the upper Amazonas basin. Bonner Zool. Beitr., 32(12): 183-194.

Lim, L.C.; Dhert, P.; Sorgeloos, P. 2003. Recent developments in the application of live feeds in the freshwater ornamental fish culture. Aquaculture, 227:319-331.

Luna-Figueroa, J. 1999. Influencia de alimento vivo sobre la reproducción y el crecimiento del pez ángel Pterophyllum scalare (Perciformes: Cichlidae). Acta Universitaria, 1:21-29.

Luna-Figueroa, J.; Figueroa-Torres, J.; Hernández de la Rosa, L. P. 2000. Efecto de alimentos con diferente contenido proteico en la reproducción del pez ángel Pterophyllum scalare variedad perlada (Pises: Cichlidae). Ciencia y Mar, 4:3-9.

Maheana, K.R.; Riveiro, R.P.; Furlan, A.C.; Neves, P.R.; Oliveira, A.C.; Faira, R.H.S.; Dambros, A. 2004. Determinação da exigencia em proteína para alevinos de acará disco (Symphysodon spp.). In: Aqua Ciência 2004; Congresso da Aquabio, 1., Vitória, 2004. Anais... Vitória: Sociedad Brasileira de Aqüicultura e Biología Aquática. p.402.

Morias, S.; Bell, J.G.; Robertson, D.A.; Roy, W.J.; Morris, P.C. 2001. Protein/lipid ratios in extruded diets for Atlantic cod (Gadusmorhua L.): effects on growth, feed utilization, muscle composition and liver histology. Aquaculture, 203:101-119. 
Moreau, M.A.; Coomes, O.T. 2007. Aquarium fish exploitation in western Amazonia: conservation issues in Peru. Environmental Conservation, 34(1):12-22.

Negrete, R. P.; Conroy, D. C.; Romero, J. J. 2008. Evaluación de la calidad bacteriológica del alimento vivo (Artemia, Daphnia, Itílico y Tubifex) para peces en los sitios de su recolección, producción y venta. Veterinaria México, 39(3): 255-268.

Ready, J. S.; Kullander, S.O. 2004. Apistogramma eremnopyge, a new species of cichlid fish (Teleostei: Cichlidae) from Peru. Zootaxa, 564: 110.

Rodrigues, L.A.; Fernandes, J.B.K. 2006. Influência do processamento da dieta no desempenho produtivo do acará bandeira (Pterophyllum scalare). Acta Scientiarum Animal Sciences, 28(1): 113-119.

Römer, U.; Hahn, I. 2008. Apistogramma sp. n.: Description of a new facultative mouth-breeding cichlid species (Teleostei: Perciformes: Geophaginae) from Northern Perú. Vertebrate Zoology, 58(1):49-66.

Römer, U.; Duponchelle, F.; Vela, A.; García-Dávila, C.; Sirvas S.; Cachay, C.D.; Renno, J-F. 2011.
Apistogramma cinilabra sp. n.: Description of a potentially endangered endemic cichlid species (Teleostei: Perciformes: Cichlidae) from the Departamento Loreto, Peru. Vertebrate Zoology, 61(1):3-23.

Ruíz, A.; Souza, J.; Vela, U. 2003. Análisis de la pesquería ornamental en Iquitos y áreas de influencia- Bases para una propuesta de manejo. Tesis de Maestría. Universidad Nacional de la Amazonía Peruana-UNAP. Iquitos, Perú. 176 pp.

Soriano, M.; Hernández, D. 2002. Tasa de crecimiento del pez ángel Pterophyllum scalare (Perciformes: Cichlidae) en condiciones de laboratorio. Acta Universitaria, 12 (2):28-33.

Santos, E.C.C.; Takahashi, L.S.; Saita, M.V.; Da Silva, T.V.; Rigobelo, E.C. 2008. Efeito de diferentes alimentos na qualidade de agua na produção de acará bandeira (Pterophyllum scalare). Anais do IV Simpósio de Ciencias da UNESP. Dracena, Brasil. 4p.

Wouters, R.; Van Horenbeek, T.; Merchie, G.; Bribson, P. 2004. Dietas secas elaboradas con ingredientes marinos frescos para larvas de camarón. Panorama Acuícola Magazine, 9(3): 5455 . 